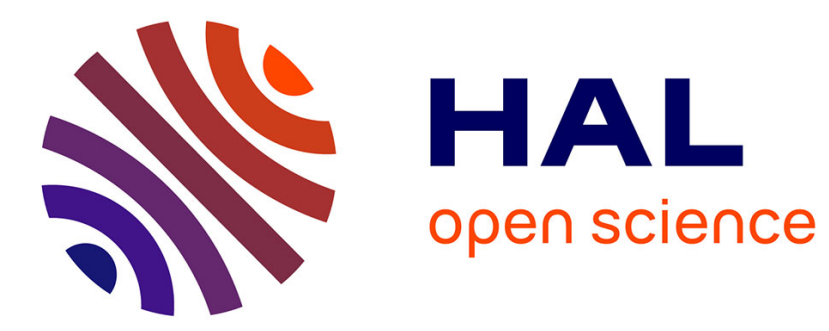

\title{
Palaeoneurology and the Emergence of Language
}

Aurélien Mounier, Camille Noûs, Antoine Balzeau

\section{To cite this version:}

Aurélien Mounier, Camille Noûs, Antoine Balzeau. Palaeoneurology and the Emergence of Language. Bulletins et Mémoires de la Société d'anthropologie de Paris, 2020, 32 (3-4), pp.147-157. 10.3166/bmsap-2020-0098 . hal-03007732

\section{HAL Id: hal-03007732 \\ https://hal.science/hal-03007732}

Submitted on 23 Nov 2020

HAL is a multi-disciplinary open access archive for the deposit and dissemination of scientific research documents, whether they are published or not. The documents may come from teaching and research institutions in France or abroad, or from public or private research centers.
L'archive ouverte pluridisciplinaire HAL, est destinée au dépôt et à la diffusion de documents scientifiques de niveau recherche, publiés ou non, émanant des établissements d'enseignement et de recherche français ou étrangers, des laboratoires publics ou privés. 


\section{Palaeoneurology and the emergence of language}

\section{Paléoneurologie et origine du langage}

3

4 Aurélien Mounier ${ }^{1,2,}{ }^{*}$, Camille Noûs ${ }^{3}$, Antoine Balzeau ${ }^{1,4}$

5

$6{ }^{1}$ Histoire Naturelle de I'Homme Préhistorique (HNHP, UMR 7194), MNHN/CNRS/UPVD, Musée de 7 I'Homme, 17 place du Trocadéro et du 11 Novembre, 75016 Paris, France.

8 '2Leverhulme Centre for Human Evolutionary Studies, Department of Archaeology, University of 9 Cambridge, Fitzwilliam Street, Cambridge CB2 1QH, United Kingdom.

$10{ }^{3}$ Laboratoire Cogitamus, Musée de l'Homme, 17 place du Trocadéro et du 11 Novembre, 75016 Paris, 11 France.

${ }^{4}$ Department of African Zoology, Royal Museum for Central Africa, B-3080 Tervuren, Belgium. 


\section{Abstract}

The origin of language has been much debated over the years. Recent research has centred the controversies on two main ideas. Language, as defined by the Basic Property formulated by Chomsky, is a characteristic unique to $H$. sapiens that developed in our species in the past 300,000 years. Other scientists argue that the Basic Property is a derived characteristic shared with other hominin species, such as $\mathrm{H}$. neanderthalensis and the last common ancestor of both modern humans and Neandertals, which evolved over a long period of time, perhaps as long as 2 million years. Palaeoneurology, which studies the phenotype of the brain in past populations, may have left this complex topic aside because of the difficulty of deducing brain morphology from endocasts (imprints of the neurocranium) and inferring function from brain morphology. In this manuscript, we review the various hypotheses on the evolution of language, highlighting the potential of palaeoneurology to help understand this complex aspect of human evolution, and provide an updated interpretation of previously published endocranial phenotypic data from fossil populations. This brings additional support to a long chronology framework for the origin of language in the hominin lineage: the basic property for modern language may have been in place from the last common ancestor of $H$. sapiens and $H$. neanderthalensis.

\section{Résumé}

L'origine du langage a suscité de nombreuses controverses au fil des ans. Des recherches récentes ont centré les débats sur deux idées principales. Le langage, tel que défini par la propriété de base de Chomsky, serait une caractéristique unique $d^{\prime} H$. sapiens qui se serait développée au sein de notre espèce durant les derniers 300000 ans. D'autres scientifiques soutiennent l'idée que la propriété de base serait une caractéristique dérivée partagée avec d'autres espèces d'hominines, telles qu' $H$. neanderthalensis et le dernier ancêtre commun aux humains modernes et aux Néandertaliens, et qui aurait évolué sur une longue période de temps, potentiellement sur 2 millions d'années. La paléoneurologie, qui étudie le phénotype du cerveau dans les populations passées, peut avoir négligé ce sujet complexe en raison des difficultés à déduire la morphologie du cerveau à partir du moulage endocrânien (empreinte du neurocrâne) et à inférer la fonction à partir de la morphologie du cerveau. Dans ce manuscrit, nous passons en revue les différentes hypothèses concernant l'évolution du langage, nous mettons en évidence le potentiel de la paléoneurologie pour aider à comprendre cette question complexe dans l'évolution humaine et nous fournissons une interprétation à jour des données phénotypiques endocrâniennes précédemment publiées provenant de populations fossiles. Nous apportons un soutien supplémentaire à un cadre chronologique long pour l'origine du langage dans la lignée humaine : la propriété de base du langage moderne dans les populations d'hominines semble avoir préexister l'apparition de la population ancestrale aux $H$. sapiens et $H$. neanderthalensis.

Keywords: palaeoneurology; Basic Property; Homo neanderthalensis; Homo sapiens; Middle Pleistocene hominins

Mots clés : paléoneurologie, propriété de base ; Homo neanderthalensis; Homo sapiens; hominines du Pléistocène moyen 
In the evolution of the genus Homo, an area of constant debate concerns the classification of fossil specimens within much discussed Homo taxa [1-4] and the abilities of those hominin species. One of the major unresolved questions concerns the emergence and evolution of language faculties.

\section{The only talking hominin}

There are different hypotheses regarding the evolution of language within the genus Homo. One of the oldest hypotheses argues that language emerged at a late stage in modern humans, perhaps as late as 100,000 years ago (ka) (see, [5-6]). This hypothesis was originally developed from the idea that the production of differentiated vowels would have been impossible without a large pharyngeal cavity. The descent of the larynx was also seen as a unique $H$. sapiens characteristic, which - de facto - limited the emergence of modern language to our species [7]. The ideas of a descended larynx as a prerequisite for producing differentiated vowels and as a unique $H$. sapiens feature have both been repeatedly contested ever since [8-9]. However, this hypothesis is still strongly supported because it is also rooted in the 'cultural modernity' hypothesis, which holds that modern humans acquired full modern human behaviour at least $100 \mathrm{ka}$ after their first appearance [10]. Advanced modern behavioural traits, which include a new techno-complex (Later Stone Age, LSA in Africa and Upper Palaeolithic in Europe) and symbolism, as demontrated by the earliest prehistoric art [11], seem to have been fully acquired by modern humans by $50-40 \mathrm{ka}$ [12]. Before that date there is little in the archaeological record linked to modern humans that shows symbolic behaviour. The earliest trace of symbolic behaviour for the $\mathrm{H}$. sapiens species can be traced back to ca $80 \mathrm{ka}$ in Blombos cave (South Africa) [13] and Taforalt (Morocco) [14]. The presence of this behavioural package is, in turn, often used to infer the emergence of modern language.

More recently the 'Why Only Us' hypothesis [15] uses the 'Basic Property' of human language as a landmark to infer the origin of language in hominin populations. Basic Property is described by Chomsky [16] as the 'Merge' operation, which builds a "discrete infinity of structured expressions that are interpretable in a definite way by the conceptual-intentional system of thought and action, and by a sensory-motor system for externalisation" (p. 201). In other words, the Basic Property refers to the way thoughts are linked with sounds and signs. For Berwick and Chomsky (15), language - as defined by the Basic Property, is also restricted to $H$. sapiens, but it must have arisen within its clade earlier than previously thought. The San populations split from the other modern human populations around 160 ka [17] and were mostly genetically isolated until 3000 years ago. Despite this genetic isolation, the modern Sans possess a fully modern human language faculty. Therefore, the Basic Property for modern language had to have appeared between the origin of the first modern humans, which by the time of Berwick and Chomsky's publication (2017) was thought to be around $200 \mathrm{ka}$, but can now be placed at around $300 \mathrm{ka}$ (see, [18-20]), and the first identified split within $H$. sapiens populations at around $160 \mathrm{ka}$ [17].

The 'Why Only Us' hypothesis relies first on the scarcity of archaeological evidence of symbolic behaviour within the Denisovan/Neandertal lineage to infer that the Basic Property must have developed within the modern human clade only after the split between the two lineages. The new date estimates for the time of the split between those lineages, 700-500 ka instead of the traditional $400 \mathrm{ka}$ (see, [21-22]), supports this hypothesis by allowing enough time to the $H$. sapiens lineage to develop genetic innovations that would ultimately lead to the acquisition of the Basic Property, and 
hence, of a fully modern human language faculty [23]. Additionally, the genetic differences identified between the Denisovan/Neandertal lineage and the modern human ones, notably in the FOXP2 genomic region [24-25] are also seen, in the 'Why Only Us' hypothesis, as evidence of the different language faculties between the two clades. While Berwick and Chomsky [23] acknowledge that it is unclear whether FOXP2 plays a role in the emergence of the Basic Property, they rely on the fact that some segments of the FOXP2 transcription factor gene of an Altaic Neandertal individual appears to have introgressed from modern humans [25], supporting the idea that both lineages accumulated genetic differences in a key part of the genome concerning language faculties and language acquisition.

\section{A long chronology for the development of modern language faculties}

At the other end of the spectrum, researchers argue for a much longer chronology in the development of modern language faculties (i.e. Basic Property). This 'Gradual Hypothesis' is, yet again, primarily based on the interpretation of hints of symbolic behaviour in the archaeological record, which in the view of the supporters of a more gradual evolution of language, does not support cultural modernity. A number of recent studies have indeed modified the paradigm regarding the appearance of symbolic behaviour by demonstrating that hominins within the $\mathrm{H}$. neanderthalensis lineage were capable of expressing advanced modern behavioural traits as defined by Klein [12]. The most spectacular discovery is the dating to $176 \mathrm{ka}$ of annular constructions of broken stalagmites which were made 336 metres deep into the Bruniquel Cave (Southwest France) [26]. Similarly, the debated [27-28] dating of cave art in the Iberian Peninsula to 64 ka [29] points to Neandertal authorship. This new chronology establishes that before the arrival of $\mathrm{H}$. sapiens in Europe, hominins had already developed advanced symbolic behaviour. Symbolic behavioural faculties in $\mathrm{H}$. neanderthalensis are also demonstrated by funerary practices [30], although the evidence has been heavily criticised [31], and the new direct dating of Neandertal hominin remains at the Grotte du Renne [32] demonstrates that the Neandertal occupation was indeed contemporary with the Châtelperronian Upper Palaeolithic techno-complex found at the site. Given this new archaeological evidence, it seems possible that symbolism was not limited to the $H$. sapiens clade alone, and that the Neandertals and possibly the common ancestor of both lineages may have been capable of similar behaviour. If these advanced behaviours are used as proxies for the Basic Property for modern language, then both the Neandertals and their ancestors would have had a language faculty that "involves a cognitive architecture that maps sounds (or gestures) into meaning through a series of combinatorial structures" [33], p. 52). One should nevertheless keep in mind that the evidence describing advanced symbolic behaviour in Neandertals remains sparse and cannot compare quantitatively with later archaeological evidence associated with Upper Palaeolithic humans.

The Gradual Hypothesis also uses the most recent genomic studies to strengthen its theoretical claim. First, it stresses the fact that both lineages interbred at least three times during their isolated genomic history. The mitochondrial DNA (i.e. mtDNA) retrieved from 'classic' (i.e. 130-40 ka) Neandertal specimens is closer to that of modern humans than it is to the mtDNA sequenced from Denisovan and Middle Pleistocene fossils from Europe that are widely considered to be early Neandertals (i.e. Sima de los Huesos), indicating some gene flow between the two lineages during the mid-Middle Pleistocene [34]. Neandertals and $H$. sapiens interbred when the latter first came into the Levant around 100-120 ka $[25,35]$ and the modern human fossils from Peștera cu Oase in Romania, which date back to 42-37 
ka, probably had a recent Neandertal ancestor (i.e. 4 to 6 generations [36]). Moreover, while the Neandertal and modern human clades show genetic distinctiveness, the actual number of differences appears to be relatively small. Prüfer and colleagues [37] showed that only 31,389 single nucleotide substitutions and 4,113 short insertions or deletions distinguished modern humans from their nearest extinct relatives, among which only about three thousand of those fixed changes could have potentially influenced gene expression [37]. Therefore, one could consider that with such an intricate genetic history between the two lineages, it is less likely that the two would have had completely distinct language faculties.

The final idea put forward by supporters of the Gradual Hypothesis is co-evolution of tool-knapping and language faculties [38-39]. This implies that the evolution of the Basic Property for modern language could have originated within the genus Homo with the Mode 2 technology (i.e. Acheulean) whose earlier appearance in the African archaeological record is documented at 1.75 million years ago [40]. This idea relies on the assumption that the transmission of skills necessary to master elaborate lithic technology demands language [33]. Experimental studies have given contrasting results when testing this hypothesis. In 2013 Uomini and Meyer showed that the pattern of cerebral blood flow lateralization was similar when participants were asked to knap Acheulean tools and to generate cued words [41]. Another study, focusing on the Oldowayen techno-complex, which appeared around 2.5 million years ago in the archaeological record, gives further support to Uomini and Meyer's results. It shows that reliance on stone tools would have triggered selection for teaching and language. One of the outcomes of this selection would have been the appearance of Acheulean, the Mode 2 technology being the first techno-complex requiring more advanced faculties in both language and teaching for its transmission [42]. However, Putt and colleagues [43] in a similar study suggest that selection from reliance on stone tools favoured the development of the prefrontal and temporal cortices, which offered a more complex toolkit to the hominins but did not play a significant role in the evolution of language.

\section{Towards a new paradigm?}

The lack of scientific consensus, which may be explained by the difficulties of evaluating traits that can only be studied through proxies (anatomical or symbolic), has led to a situation where the study of language evolution is often considered as out of reach for current research capacities. The first aim of the Globularity hypothesis (i.e. Globularization Leads to our Brain's Language-Readiness) developed by Boeckx [44], is to offer an updated framework for the study of language evolution. The globularity hypothesis distinguishes between language and language-readiness, in other words, the anatomical and physiological prerequisites for language acquisition and use are not sufficient and inputs from cultural evolution studies are necessary to understand the complexity of grammatical systems that need to be learned by children. The Globularity hypothesis aims to focus on the neurobiological properties that would need to be linked to the anatomical and physiological preconditions for a 'language-ready brain'. This hypothesis sets out to investigate the phenotypes of both brain and braincase, given their tightly correlated developmental trajectories, in order to draw inferences from skull size and shape changes about the organ that generates language. For instance, Boeckx [44] links the formation of a fronto-parietal-temporal loop that would provide an indirect pathway for language 
connection between areas of the brain believed to be part of this language loop (i.e. Broca's and Wernicke's regions, see below). The expansion of the parietal region is part of the globularization process within the hominin lineage [47-48] that may have played a role in the formation of a language network. The Globularity hypothesis supports a rather late evolution of the Basic Property within the modern human lineage, as one of its components relies on the hypothesis of self-domestication [4950] which would have led to the appearance of the modern human phenotype. This is congruent with morphometric studies on encephalization trajectories within the Homo lineage, where $\mathrm{H}$. sapiens appears to present a different globularization trajectory, possibly triggered by the expansion of the parietals [47], which may have happened late in the evolution of modern humans [51]. However, the unique approach to language evolution consisting of linking the study of brain and neurocranium phenotypes is important for any advances in the field.

\section{Language evolution and palaeoneurology}

Palaeoanthropology has long been studying the phenotypes of the calvarium and the brain, through the study of casts of the inner surface of the neurocranium (i.e. endocasts) of fossil specimens (e.g. [52-55]). However, apart from a few exceptions (e.g. [56-58]), the implications of specific anatomical features for language evolution are often overlooked. First, the object of the study in palaeoneurology, the endocast, is a schematic representation of the brain's anatomy, and may not be regarded as a reliable source of information. Its morphology must be considered carefully, especially when discussing function. Secondly, there are few studies combining data on the morphology of the endocast and of the neurocranium. To address the former, Kochiyama and colleagues [59] estimated the possible shape of the actual brain of fossil Neandertals and Early $\mathrm{H}$. sapiens in order to compare it with the brain morphology of living populations. Their results confirmed that both Early and extant $H$. sapiens presented a larger cerebellum than the Neandertals [60]. The cerebellum is linked to higher cognition, including language [61-62], and the morphological differences identified between the two species may indicate distinct language faculties. Gunz and colleagues [63] went further by deriving an index of endocranial shape based on the actual morphologies of living people's brains using MRI scans. They then estimated this shape index in fossil specimens and compared it with the shape of the neurocranium and with gene expression data. Their results show that introgressed Neandertal alleles correlate with reduced globularity of the endocranium shape in modern humans, thus demonstrating the potential of their approach. Nevertheless, clarifying the correlation between morphology and function will require further work, and traditional approaches in palaeoneurology should also be considered as they can bring interesting insights regarding language evolution.

These approaches rely on the study of areas of the brain that are traditionally identified as playing a part in the classic language loop: the Wernicke-Geschwind model [64-65]. This model describes how different areas of the brain are involved in language comprehension and in language production [66]. One of the major issues regarding the Wernicke-Geshwind model lies in the fact that the definitions of the regions involved in this language loop are still much debated and the usefulness of the model itself is sometimes questioned. For instance, Tremblay and Dick [67] showed that scientists did not agree on the actual anatomical definition of the Broca and Wernicke areas. They conducted a survey in which scientists were asked to choose between seven different definitions for each area. While $73 \%$ of the scientists recognised Broca's area in two similar definitions, four definitions of the Wernicke area were 
needed to reach a similar percentage (i.e. 70\%, see Fig. 1). Alternatives to this model are, however, not easy to implement (see, for instance, the fronto-parietal-temporal loop discussed by Boeckx [44]), while the anatomical regions referred to in the Wernicke-Geschwind model can be linked to wellknown areas of the brain as defined by Brodmann [68]. Broca's area generally encompasses areas 44 and 45, while Wernicke's area most often refers to area 39, part of areas 40 and 22. In palaeoneurology, Broca's area may cover approximately the morphology of the third frontal convolution (i.e. $3 \mathrm{Fc}$ ), which encompasses areas 44 and 45 as part of area 10 . Wernicke's area is more difficult to define on endocasts, but part of it, the angular and supramarginal gyri, correspond to Brodmann's areas 39 and 40 respectively and can be identified (see, Fig. 1 and [54, 56, 69]). The development and definition of the $3 \mathrm{Fc}$ and of the angular and supramarginal gyri as observed in palaeoneurology correspond to a certain extent to the most common definitions of the Broca and Wernicke areas (see Fig 1 and [67]). Therefore, and despite the current debates on the WernickeGeschwind model [67], those anatomical regions and their bilateral variations as observed on endocasts remain the most direct source of anatomical information for palaeoanthropologists discussing language evolution in fossil populations.

\section{Figure 1}

Mounier and colleagues [70] used parsimony to analyse a coded morphological database of fossil hominins from the genus Homo which considered both ecto and endocranial morphologies. The aim of the analysis was to test whether the anatomy of the endocast contributed to the phylogenetic differential definition of $\mathrm{H}$. neanderthalensis from $\mathrm{H}$. sapiens. However, the morphological features identified as responsible for the separation of the two species are mostly located on the ectocranial and not on the endocranial surface. Amongst the 35 endocranial features considered in the study, 10 are related to either Broca (characters \#14 -Definition and development of the relief of the head of 3Fc, \#15 -Definition and development of the relief of the foot of the 3Fc, \#16 -Orientation of the anterior and posterior ramus of the Sylvian valley, \#17 -Lateral development of the pars triangularis, \#18 -Sagittal development of the pars triangularis, \#19 -Maximum length position between pars triangularis, and \#20 -Position of the base of the pars triangularis relative to the temporal pole) or Wernicke areas (\#22 -Definition and projection of the supra-marginal gyrus, \#23 -Form of the supramarginal gyrus, \#24 -Definition of the lobule of the angular gyrus). None of the endocranial characters considered in the cladistic analysis were identified as a full apomorphy for the Neandertal and $\mathrm{H}$. sapiens clades, but four, \#1 (cranial capacity), \#16, \#22 and \#30 (position of the occipital lobes), are apomorphies for both clades. Focusing on the 10 characters that describe morphologies linked to the language loop, we note that some are variable within and outside taxa of the genus Homo, but others mark the emergence of important clades. For instance, three characters describing the $3 \mathrm{Fc}$, hence Broca's area (i.e. \#14 well-developed head of the third frontal convolution, \#16 upward and frontward orientation of the anterior and posterior ramus of the Sylvian valley, and \#17 well-developed pars triangularis), are newly emerged morphological features that separate Neandertals, modern humans and their last common ancestor from $\mathrm{H}$. erectus sensu lato and most of the Middle Pleistocene fossils (Fig. 2). This is also true for Wernicke's area: both the lobule of the angular gyrus (\#24) and the supramarginal gyrus (\#22) become strongly developed and well defined just before the split between 
Neandertals and modern humans. A recent study [71] found that the area of the endocast where both features can be observed appears slightly more spread out in $\mathrm{H}$. sapiens. However, they did not study the angular and supramarginal gyri in detail but focused instead on the shape of the parietal lobe. Moreover, a well-defined and projected supramarginal gyrus constitutes a true synapomorphy for both the Neandertal and modern human clades (Fig. 2). The definition and development of the relief of the head of 3Fc (\#14), the lateral development of the pars triangularis (\#17), the maximum length position between pars triangularis (\#19) and the definition of the lobule of the angular gyrus (\#24) are not true synapomorphies in this analysis, as they undergo reversion in individual specimens within the Neandertal (i.e. Gibraltar 1, Spy 1 and Saccopastore 1) and H. sapiens (i.e. Hofmeyr) clades. Those reversions prevent morphologies that could yield information regarding the language loop from appearing as derived features common to Neandertals and modern humans. However, it should be noted that the study did not focus on these particular anatomical traits, and that the endocast sample was not chosen for this purpose. More specimens could have been added to the study if it had focused on morphologies linked to the language loop. Instead, the state of preservation of the endocasts considered by Mounier and colleagues [70] is sometimes unsatisfactory, for instance the left side of the calvarium of Hofmeyr and Gibraltar 1 is virtually absent, and the reported observations of characters \#14 (definition and development of the relief of the head of 3Fc), \#17 (lateral development of the pars triangularis), \#19 (maximum length position between pars triangularis) and \#24 (definition of the lobule of the angular gyrus) are necessarily based on some degree of interpolation. Therefore, these reversions should not prevent us from highlighting the underlying patterns, which show the appearance, throughout the Middle Pleistocene hominin fossil record, of anatomical features related to areas of the brain which have been described as playing a role in language [66]. Finally, Mounier and colleagues [70] identify an additional character which is not a true synapomorphy, but which plays a role in the definition of the modern human and the Neandertal clades. Character \#33 defines the size of the sulcus separating the cerebellar lobes, and in most Neandertals the sulcus is wider than in most modern humans. It is linked to higher cognition, including language [61-62], in spite of not being part of the classic language loop. This indicates a possible increase in the size of the cerebellar lobes in modern humans [59-60], which could have had an impact on $H$. sapiens language faculties (see, [59, 72]).

It is interesting to note that many of the characters identified in the sequence of appearance, during the Middle Pleistocene, of anatomical features related to the language loop on hominin endocasts are focused on the 3Fc (i.e. \#14, 16, 17 and 19). In 2014, Balzeau and colleagues [56] quantified and analysed the bilateral variation in size and shape of the 3Fc within Pan, Australopithecus and Homo specimens (including an expanded Neandertal sample, see Fig. 3): the study demonstrated that the 'Broca's cap' identified in hominins was due to a size reduction of the 3Fc in the left hemisphere when compared to the right one. The left $3 \mathrm{Fc}$ is indeed shorter but presents a similar width making its shape more compact, hence increasing its morphological distinctiveness. We have expanded our Neandertal samples since our original study [56]. Figure 3 presents the comparison of the size of the third frontal convolution and the endocranial volume, expressed respectively as their square-root and their cube- 
root. In addition, the mean surface (in $\mathrm{mm}^{2}$ ) of this anatomical area in the Neandertal sample (167.7, $\mathrm{SD}=32.7, \mathrm{~N}=11$ ) is larger than the ones observed in both fossil Homo sapiens $(133.5, \mathrm{SD}=30.6, \mathrm{n}=8)$ and in the Homo erectus sample (110.6, SD=24.4, $\mathrm{N}=12$ ). The small sample sizes of the groups analysed make it difficult to identify statistical correlations within our data. Nevertheless, the observed global variation throughout human evolution, as illustrated by these mean values and by the distribution of the specimens for each sample in Figure 3, appears to show a size gradient for this anatomical area between hominin species. When only the hominin sample is considered, there is a significant correlation between $3 \mathrm{Fc}$ and the endocranial volume (RMA regression, $r=0.19, p=0.008$ ). Moreover, the gradient of the degree of asymmetry as seen directly on the endocasts and partly observed through morphometric data on small fossil samples [56], i.e. the distinctiveness of the morphology of the 3Fc on the left hemisphere, sets Neandertals and modern humans apart from the rest of the sample. The sparseness of the fossil record prevents us from performing a more detailed comparative morphometric analysis of the departure from symmetry of the third frontal convolution in hominin species. Nevertheless, our morphometric data showing the increase in size of this anatomical area in recent hominin species concords with the repeated observation of a well-defined Broca's area in $\mathrm{H}$. sapiens, Neandertals and a few Middle Pleistocene fossils (i.e. H. heidelbergensis sensu lato) when compared to other fossil hominins and Pan specimens [56]. Although these results should not be interpreted as directly inferring speech capacities, nor as a direct characterisation of the functional area related to speech, they are nevertheless based on morphological observations which constitute the best available proxy for analysing Broca's cap in fossil hominins [56, 69]. Similarly, and as we demonstrated above, other anatomical features of the endocast appear to be poorly delimited in hominins or even absent in great apes [54-55]. In particular, the reliefs of the angular and supramarginal gyri are only identifiable in Neandertals, modern humans and some Middle Pleistocene fossils $[54,70]$. Their definition is too faint to allow any reproducible quantification on endocasts and these characters were not considered by Balzeau and colleagues [56].

\section{Figure 3}

Therefore, both analyses of the endocast morphology - through different methodological approaches - identify a clear separation of modern humans and Neandertals from other hominid species, despite known differences between these taxa (e.g. the relative contribution of the frontal, parieto-temporal and occipital lobes [73]). In this context, the morphologies responsible for such a split in the hominid clade are linked to the classic Wernicke-Geschwind model and it could be argued that they form a morphological substrate of characteristics present in both Neandertals and modern humans that are possibly linked to Chomsky's Basic Property for language. Indeed, the 3Fc and the angular gyrus have been repeatedly associated with language processing, one controlling for muscles related to speech [74] and the other having a role in the transformation of visual representations into an auditory code [75]. The function of the supramarginal gyrus, and despite its position on the brain (Brodmann's area 40 ), is less clear; it has nevertheless been described as being involved with language comprehension [76]. The only highlighted difference between Neandertals and modern humans concerns the cerebellum which, from about 100,000 years ago, gradually became larger in H. sapiens [51, 59, 70, 72]. The cerebellum plays a role in higher cognition and possibly language, but is not part of the classic 
language loop and it is unclear whether it influenced language faculties. Nevertheless, the development of these anatomical features throughout the Middle Pleistocene and their presence in both $H$. sapiens and $H$. neanderthalensis suggest that both species would have had similar language faculties despite the fact that their general brain structure presents anatomical differences.

\section{Origin of language - more questions than answers}

The literature review presented in this paper shows a complex picture of the evolution of language. It remains difficult to decipher which hominin population developed the Basic Property which gave hominins modern language, and when. The study of endocasts, which is often overlooked when discussing the evolution of language, may nevertheless bring new insights to the debate. The identification of an endocranial anatomical substrate possibly linked to language and common to $H$. neanderthalensis, $H$. sapiens and their ancestor $[56,70]$ must be discussed within the wider debate surrounding the origin of language. In recent years, palaeogenomics has profoundly transformed the status of $H$. neanderthalensis, which now stands much closer to modern humans, given the accumulating evidence regarding interbreeding between the modern and Neandertal lineages $[25,34-$ 36]. Moreover, evidence of complex behaviour (e.g. advanced modern behaviour [12]) outside of the modern human clade [26, 29-30], along with experimental studies showing possible co-evolution of tool-knapping and language faculties [41-42], supports the possibility of common, or at least close, language faculties between both lineages.

However, one should keep in mind that the same evidence is sometimes used to demonstrate the exact opposite: genomics data, despite interbreeding, show that the lineages were separated [23], evidence of advanced modern behaviour outside of the modern clade is much discussed [31] and experimental studies on tool-knapping may reach a different conclusion [43]. This is also why palaeoneurology can be of importance in helping to resolve the debate surrounding the origin of language, even though demonstrating the presence of the morphological traits required to develop the Basic Property for modern language does not demonstrate the presence of the ability itself, as it cannot be observed in the fossil record (see for instance [77]).

The origin of language remains a difficult topic, but new approaches $[59,63]$, and the study of both the calvarium and endocranial morphologies, as advocated by Boeckx [44] may bring a more robust answer in the near future, and palaeoneurology through the study of endocasts will certainly play a role in this.

\section{Acknowledgments.}

For permission to study specimens in their care we thank the directors and curators of the following institutions: Aristotle University of Thessaloniki (Thessaloniki, Greece); Campus Gasthuisberg (Leuven, Belgium); CHNO des XV-XX, (Paris, France); Indonesian Centre for Archaeology (Jakarta, Indonesia); Institut de Paléontologie Humaine (Paris, France); Mpu Tantular Museeum (Surabaya, Indonesia); Musée de l'Homme (Paris, France); Museo di Antropologia G. Sergi (Sapienza Universitá di Roma, Italy); Museo Nacional de Ciencas Naturales (Madrid, Spain); Museo preistorico-etonografico L. Pigorini (Rome, Italy); National Museum (Bloemfontein, Republic of South Africa); National Museums of Kenya (Nairobi, Kenya); Natural History Museum (London, UK); Duckworth Collection (University of 

Museum for Central Africa (Tervuren, Belgium); Soprintendenza Archeologia del Lazio (Rome, Italy); Staatliches Museum für Naturkunde (Stuttgart, Germany); University of Edinburgh (Edinburgh, UK); University of Vienna (Vienna, Austria); University of Wollongong (Wollongong, Australia). We thank I. Crevecoeur, P. Gunz, S. Neubauer and F. Grine for providing CT scans of specimens in their care. We are also grateful to M. Caparros, E. Gilissen, D. Grimaud-Hervé, R. Holloway and S. Prima. The study was funded in part by the Fyssen Foundation (postdoctoral grant for AM) and by the Paul Broca II project, 6th European Community Framework Programme (CT scanning of apes). Finally, we thank the Editor of the BMSAP (S. Kacki), and two anonymous reviewers for valuable comments and criticisms of earlier drafts that contributed to the improvement of this study.

403

404

405

406

407

408

409

410

411

412

413

414

415

416

417

418

419

420

421

422

423

424

425

426

427

428

429

430

431

432

433

434

435

436

437

438

439

\section{References}

1. Argue D, Groves CP, Lee MSY, et al (2017) The affinities of Homo floresiensis based on phylogenetic analyses of cranial, dental, and postcranial characters. J Hum Evol 107:107-33

2. Dembo M, Matzke NJ, Mooers $A \varnothing$, et al (2015) Bayesian analysis of a morphological supermatrix sheds light on controversial fossil hominin relationships. Proc R Soc B 282(1812):20150943 3. Wood B, Lonergan N (2008) The homini fossil record: taxa, grades and clades. J Anat 212:35476

4. Mounier A, Caparros M (2015) The phylogenetic status of Homo heidelbergensis - a cladistic study of Middle Pleistocene hominins. BMSAP 27:110-34

5. Berwick R, Hauser M, Tattersall I (2013) Neanderthal language? Just-so stories take center stage. Front Psychol 4:671

6. Bolhuis JJ, Tattersall I, Chomsky N, et al (2014) How Could Language Have Evolved? PLOS Biol 12(8):e1001934

7. Lieberman PH, Klatt DH, Wilson WH (1969) Vocal Tract Limitations on the Vowel Repertoires of Rhesus Monkey and other Nonhuman Primates. Science 164(3884):1185-87

8. Fitch WT, Reby D (2001) The descended larynx is not uniquely human. Proc Biol Sci 268(1477):1669-75

9. Boë L-J, Sawallis TR, Fagot J, et al (2019) Which way to the dawn of speech?: Reanalyzing half a century of debates and data in light of speech science. Sci Adv 5(12):eaaw3916

10. Conard N (2010) Cultural modernity: Consensu or conundrum? Proc Natl Acad Sci USA 107(17):7621-22

11. Aubert M, Lebe R, Oktaviana AA, et al (2019) Earliest hunting scene in prehistoric art. Nature 576:442-445

12. Klein RG (2008) Out of Africa and the Evolution of Human Behavior. Evol Anthropol 17:267-81

13. Errico (d') F, Henshilwoodc C, Vanhaerend M, et al (2005) Nassarius kraussianus shell beads from Blombos Cave: evidence for symbolic behaviour in the Middle Stone Age. J Hum Evol 48(1):3-24

14. Bouzouggar A, Barton N, Vanhaeren M, et al (2007) 82,000-year-old shell beads from North Africa and implications for the origins of modern human behavior. Proc Natl Acad Sci USA 104(24):9964-69

15. Berwick RC, Chomsky N (2016) Why only us. . MIT Press, Cambridge, MA, $224 \mathrm{p}$

16. Chomsky N (2017) The language capacity: architecture and evolution. Psycho Bull Rev 24(1):200-03

17. Mallick S, Li H, Lipson M, et al (2016) The Simons Genome Diversity Project: 300 genomes from 142 diverse populations. Nature 538:201-06

18. Mounier A, Mirazón Lahr M (2019) Deciphering African late middle Pleistocene hominin diversity and the origin of our species. Nat Commun 10(1):3406

19. Schlebusch CM, Malmström H, Günther T, et al (2017) Southern African ancient genomes estimate modern human divergence to 350,000 to 260,000 years ago. Science $358(6363): 652-55$ 
20. Hublin J-J, Ben-Ncer A, Bailey SE, et al (2017) New fossils from Jebel Irhoud, Morocco and the pan-African origin of Homo sapiens. Nature 546(7657):289-92

21. Meyer M, Arsuaga J-L, de Filippo C, et al (2016) Nuclear DNA sequences from the Middle Pleistocene Sima de los Huesos hominins. Nature 531(7595):504-07

22. Mounier A, Mirazón Lahr M (2016) Virtual Ancestor Reconstruction: revealing the ancestor of modern humans and Neandertals. J Hum Evol 91:57-72

23. Berwick RC, Chomsky N (2017) Why only us: Recent questions and answers. J Neurolinguist 43:166-77

24. Sankararaman S, Mallick S, Patterson N, et al (2016) The Combined Landscape of Denisovan and Neanderthal Ancestry in Present-Day Humans. Curr Biol 26 (9):1241-47

25. Kuhlwilm M, Gronau I, Hubisz MJ, et al (2016) Ancient gene flow from early modern humans into Eastern Neanderthals. Nature 530:429

26. Jaubert J, Verheyden S, Genty D, et al (2016) Early Neanderthal constructions deep in Bruniquel Cave in southwestern France. Nature 534 (7605):111-14

27. White R, Bosinski G, Bourrillon R, et al (2020) Still no archaeological evidence that Neanderthals created Iberian cave art. J Hum Evol 144:102640

28. Hoffmann DL, Standish CD, García-Diez M, et al (2020) Response to White et al.'s reply: 'Still no archaeological evidence that Neanderthals created Iberian cave art'. J Hum Evol 144:102810

29. Hoffmann DL, Standish CD, García-Diez M, et al (2018) U-Th dating of carbonate crusts reveals Neandertal origin of Iberian cave art. Science 359(6378):912-15

30. Rendu W, Beauval C, Crevecoeur I, et al (2013) Evidence supporting an intentional Neandertal burial at La Chapelle-aux-Saints. Proc Natl Acad Sci USA 111(1):81-86

31. Dibble HL, Aldeias V, Goldberg P, et al (2015) A critical look at evidence from La Chapelle-auxSaints supporting an intentional Neandertal burial. J Archaeol Sci 53(Supplement C):649-57

32. Welker F, Hajdinjak M, Talamo S, et al (2016) Palaeoproteomic evidence identifies archaic hominins associated with the Châtelperronian at the Grotte du Renne. Proc Natl Acad Sci USA 113(40):11162-67

33. Dediu D, Levinson SC (2018) Neanderthal language revisited: not only us. Curr Opin Behavi Sci 21:49-55

34. Posth C, Wißing C, Kitagawa K, et al (2017) Deeply divergent archaic mitochondrial genome provides lower time boundary for African gene flow into Neanderthals. Nat Commun 8:16046

35. Vernot B, Tucci S, Kelso J, et al (2016) Excavating Neandertal and Denisovan DNA from the genomes of Melanesian individuals. Science 352(6282):235-39

36. Fu Q, Hajdinjak M, Moldovan OT, et al (2015) An early modern human from Romania with a recent Neanderthal ancestor. Nature 524:216-19

37. Prüfer K, Racimo F, Patterson N, et al (2014) The complete genome sequence of a Neanderthal from the Altai Mountains. Nature 505(7481):43-49

38. Corballis MC (2014) The gradual evolution of language. HumanaMente J Philos S 27:39-60

39. Stout D, Toth N, Schick K, et al (2008) Neural correlates of Early Stone Age toolmaking: technology, language and cognition in human evolution. Philos T R Soc B 363(1499):1939-49

40. Lepre CJ, Roche H, Kent DV, et al (2011) An earlier origin for the Acheulian. Nature 477(7362):82-85

41. Uomini NT, Meyer GF (2013) Shared Brain Lateralization Patterns in Language and Acheulean Stone Tool Production: A Functional Transcranial Doppler Ultrasound Study. PLOS ONE 8(8):e72693

42. Morgan TJH, Uomini NT, Rendell LE, et al (2015) Experimental evidence for the co-evolution of hominin tool-making teaching and language. Nat Commun 6:6029

43. Putt SS, Wijeakumar S, Franciscus RG, et al (2017) The functional brain networks that underlie Early Stone Age tool manufacture. Nat Hum Behav 1(6):0102

44. Boeckx C (2017) The language-ready head: Evolutionary considerations. Psychon Bull Rev 24(1):194-99

45. Friederici AD (2012) The cortical language circuit: from auditory perception to sentence comprehension. Trends Cogn Sci 16(5):262-68 
46. de Diego-Balaguer R, Martinez-Alvarez A, Pons F (2016) Temporal attention as a scaffold for language development. Front Psychol 7:44

47. Bruner E, Manzi G, Arsuaga JL (2003) Encephalization and allometric trajectories in the genus Homo: Evidence from the Neandertal and modern lineages. Proc Natl Acad Sci USA 100(26):15335-40 48. Neubauer S, Gunz P, Hublin J-J (2010) Endocranial shape changes during growth in chimpanzees and humans: A morphometric analysis of unique and shared aspects. J Hum Evol 59(5):555-66

49. Theofanopoulou C, Gastaldon S, O'Rourke T, et al (2017) Self-domestication in Homo sapiens: Insights from comparative genomics. PLOS ONE 12(10):e0185306

50. Zanella M, Vitriolo A, Andirko A, et al (2019) Dosage analysis of the 7q11.23 Williams region identifies BAZ1B as a major human gene patterning the modern human face and underlying selfdomestication. Sci Adv 5(12):eaaw7908

51. Neubauer S, Hublin J-J, Gunz P (2018) The evolution of modern human brain shape. Sci Adv 4(1):eaao5961

52. Bruner E (2018) Human paleoneurology: Shaping cortical evolution in fossil hominids. J Comp Neurol 527(10):1753-65

53. Holloway RL (2008) The Human Brain Evolving: A Personal Retrospective. Annu Rev Anthrop 37(1):1-19

54. Grimaud-Hervé D (1997) L'évolution de l'encéphale chez Homo erectus et Homo sapiens. Exemples de l'Asie et de l'Europe. CNRS Editions, Paris, $405 \mathrm{p}$

55. Holloway RL, Broadfield DC, Yuan MS (2004) The Human Fossil Record. Brain Endocasts: The Paleoneurological Evidence. Wiley, Hoboken, New Jersey, $315 \mathrm{p}$

56. Balzeau A, Gilissen E, Holloway RL, et al (2014) Variations in size, shape and asymmetries of the third frontal convolution in hominids: Paleoneurological implications for hominin evolution and the origin of language. J Hum Evol 76:116-28

57. Albessard-Ball L, Balzeau A (2018) Of Tongues and Men: A Review of Morphological Evidence for the Evolution of Language. J Lang Evol 3(1):79-89

58. Beaudet A (2017) The Emergence of Language in the Hominin Lineage: Perspectives from Fossil Endocasts. Front Hum Neurosci 11:427

59. Kochiyama T, Ogihara N, Tanabe HC, et al (2018) Reconstructing the Neanderthal brain using computational anatomy. Sci Rep 8(1):6296

60. Bruner E (2008) Comparing Endocranial Form and Shape Differences in Modern Humans and Neandertals: a Geometric Approach. PaleoAnthropology 2008:93-106

61. Schmahmann JD, Sherman JC (1998) The cerebellar cognitive affective syndrome. Brain 121 (4):561-79

62. Stoodley CJ, Schmahmann JD (2009) Functional topography in the human cerebellum: A metaanalysis of neuroimaging studies. Neurolmage 44(2):489-501

63. Gunz P, Tilot AK, Wittfeld K, et al (2019) Neandertal Introgression Sheds Light on Modern Human Endocranial Globularity. Curr Biol 29(1):120-27.e5

64. Geschwind N (1970) The Organization of Language and the Brain. Science 170(3961):940-44

65. Wernicke C (1908) The symptom-complex of aphasia. In: Church A (ed) Diseases of the Nervous System, Appleton, New York, pp 265-324

66. Toga AW, Thompson PM (2003) Mapping brain asymmetry. Nat Rev Neurosci 4:37

67. Tremblay P, Dick AS (2016) Broca and Wernicke are dead, or moving past the classic model of language neurobiology. Brain Lang 162(Supplement C):60-71

68. Brodmann K (1909) Vergleichende Lokalisationslehre der Großhirnrinde : in ihren Prinzipien dargestellt auf Grund des Zellenbaues. Barth, Leipzig, Germany, $324 \mathrm{p}$

69. Keller SS, Crow T, Foundas A, et al (2009) Broca's area: Nomenclature, anatomy, typology and asymmetry. Brain Lang 109(1):29-48

70. Mounier A, Balzeau A, Caparros M, et al (2016) Brain, calvarium, cladistics: A new approach to an old question, who are modern humans and Neandertals? J Hum Evol 92:22-36 
543 71. Pereira-Pedro AS, Bruner E, Gunz P, et al (2020) A morphometric comparison of the parietal 544 lobe in modern humans and Neanderthals. J Hum Evol 142:102770

545 72. Weaver AH (2005) Reciprocal evolution of the cerebellum and neocortex in fossil humans. Proc 546 Natl Acad Sci USA 102(10):3576-80

547 73. Balzeau A, Holloway RL, Grimaud-Hervé D (2012) Variations and asymmetries in regional brain 548 surface in the genus Homo. J Hum Evol 62(6):696-706

549 74. Binder J (2000) The new neuroanatomy of speech perception. Brain 123(12):2371-72

$55075 . \quad$ Price CJ (2000) The anatomy of language: contributions from functional neuroimaging. J Anat 551 197(3):335-59

552 76. Leichnetz GR (2011) Supramarginal Gyrus. In: Kreutzer JS, DeLuca J, Caplan B (eds) Encyclopedia of Clinical Neuropsychology. Springer New York, New York, pp 2439-40 77. Bruner E, Bondioli L, Coppa A, et al (2016) The endocast of the one-million-year-old human cranium from Buia (UA 31), Danakil Eritrea. Am J Phys Anthropol 160(3):458-68 
Figure 1. (2 columns)

560

561

562

563

564

565

566

567

568

569

570

571

572

573

574

575

\section{6}

577

578

579

580

581

582

583

584

585

586

587

588

589

590

591

592

593

594

595

596

597

598

599

600

601

602

603

604

605

606

(a to f) Most common anatomical definitions of Wernicke's area (a to d) and Broca's area (e and f) on the brain. These definitions of each area have been endorsed by $70 \%$ (Wernicke, respectively $26 \%, 23 \%, 12 \%$ and $9 \%$ ) and $73 \%$ (Broca, respectively $50 \%$ and $23 \%$ ) of the respondents to the Tremblay and Dick survey [67]. (g) Anatomical region of the endocast linked with Broca's area (green): 3Fc (third frontal convolution) and Wernicke's area (violet): A. gyrus (angular gyrus) and S. gyrus (supramarginal gyrus) on the endocast of a modern Australian (AUS047, Duckworth Collection). Despite the uncertainties regarding the definitions of both areas on the brain, the use of the $3 \mathrm{Fc}$, angular and supramarginal gyri appears as the most reasonable proxy to observe changes related to those areas in palaeoneurology. I ( $a$ à f) Définitions anatomiques les plus courantes de la zone de Wernicke (a à d) et de la zone de Broca (e et f) sur le cerveau. Ces définitions de chaque zone ont été approuvées par 70\% (Wernicke, respectivement 26\%, 23\%, $12 \%$ et $9 \%$ ) et $73 \%$ (Broca, respectivement $50 \%$ et $23 \%$ ) des répondants à l'enquête de [67]. (g) Région anatomique de l'endocrâne liée à la zone de Broca (vert) : 3Fc (troisième circonvolution frontale) et région de Wernicke (violet) : A. gyrus (gyrus angulaire) et S. gyrus (gyrus supramarginal) sur l'endocrâne d'un Australien moderne (AUS047, Duckworth Collection). Malgré les incertitudes concernant les définitions des deux zones du cerveau, l'utilisation de la 3Fc, des gyri angulaire et supramarginal apparaît comme le proxy le plus raisonnable pour observer les changements liés à ces zones en paléoneurologie.

\section{Figure 2. (2 columns)}

Cladogram of the genus Homo modified from Mounier and colleagues [70] presenting the most important changes along the branch of the tree (true synapomorphies $-R l=1$, and characters with $R l>0.8$ ) along with the appearance of derived features related to the classic Wernicke-Geschwind model throughout the Middle Pleistocene and before the split between the modern and Neandertal lineages (\#14 and 17 respectively $R I=0.667$ and $R I=0.75$ due to reversions). \#33 is not linked to the language loop but has been linked to the evolution of language (e.g. [59]). The endocast used to display the morphological features are, from top to bottom: Kabwe 1 (oblique view, left side), Kabwe 1 (norma lateralis), Irhoud 2 (norma lateralis) and AUS 047. Character descriptions: \#1, Cranial capacity; \#7, Number of ramifications of the middle meningeal system; \#14, Definition and development of the relief of the head of 3Fc; \#16, Orientation of the anterior and posterior ramus of the Sylvian valley; \#17, Lateral development of the pars triangularis; \#19, Maximum length position between pars triangularis; \#20, Position of the base of the pars triangularis relative to the temporal pole; \#22, Definition and projection of the supra-marginal gyrus; \#24, Definition of the lobule of the angular gyrus; \#30, Position of the occipital lobes; \#33, Width of the sulcus separating the cerebellar lobes; \#50, Presence of a tuber parietale; \#55, Form of the outline of the planum occipital in norma occipitalis; \# 56, Presence of a suprainiac fossa; \#57, Definition of the torus occipitalis transversus; \#60, Form of the outline of the superior border of the temporal squama. / Cladogramme du genre Homo modifié de Mounier et collaborateurs [70] présentant les changements les plus importants le long de la branche de l'arbre (vraies synapomorphies $-\mathrm{Rl}=1$, et caractères avec $\mathrm{Rl}>0,8$ ) ainsi que l'apparition de caractéristiques dérivées liées au classique Modèle de Wernicke-Geschwind tout au long du Pléistocène moyen et avant la scission entre les lignées modernes et néandertaliennes (\# 14 et 17 respectivement $\mathrm{RI}=0,667$ et $\mathrm{Rl}=0,75$ en raison des inversions). \# 33 n'est pas lié à la boucle linguistique mais a été lié à l'évolution du langage (e.g. [59]). L'endocrâne utilisé pour afficher les caractéristiques morphologiques est de haut en bas: Kabwe 1 (vue oblique, côté gauche), Kabwe 1 (norma lateralis), Irhoud 2 (norma lateralis), et AUS 047. Descriptions des caractères : \# 1, Capacité crânienne; \# 7, Nombre de ramifications du système méningé moyen; \# 14, Définition et développement du relief de la tête de la troisième circonvolution centrale ; \# 16, Orientation du ramus antérieur et postérieur de la scissure de Sylvius; \# 17, Développement latéral de la pars triangularis; \# 19, Position de la longueur maximale entre les pars triangularis; \# 20, Position de la base de la pars triangularis par rapport au pôle du lobe temporal ; \# 22, Définition et projection de la supra- gyrus marginal ; \# 24, Définition du lobule du gyrus angulaire ; \# 30, Position des lobes occipitaux ; \# 33, Largeur du sulcus séparant les lobes cérébelleux ; \# 50, Présence d'un tuber parietale ; \# 55, Forme du contour du planum occipital in norma occipitalis ; \# 56, Présence d'une fosse suprainiaque ; \# 57, Définition du torus occipitalis transversus ; \# 60, Forme du contour du bord supérieur de l'écaille de l'os temporal. 


\section{Figure 3. (1.5 columns)}

609 Bivariate plot of the size of the third frontal convolution (square root, noted $3 \mathrm{Fc}$, in $\mathrm{mm}$ ) and of the endocranial volume (cube root, noted Endo $\mathrm{V}$, in $\mathrm{mm}$ ) in Pan paniscus (triangles), Pan troglodytes (inverted triangles), $H$. sapiens (circles), fossil H. sapiens (black circles), fossil hominins (black diamonds: T: Taung, 17k: KNM-WT 17000, 1470: KNM-ER 1470, 1813: KNM-ER 1813, 3733: KNM-ER 3733, 3883: KNM-ER 3883, 15k: KNM-WT 15000, OH 9, D: Dmanisi 9002, T2: Trinil 2, S2: Sangiran 2, S17: Sangiran 17, M: Mojokerto, Ng7: Ngandong 7, Ng12: Ngandong 12, Sm3: Sambungmacan 3, S3: Zhoukoudian Ckn.E 1.PA.16, S12: Zhoukoudian Ckn.L 2.PA.100, LB 1: Liang Bua 1, SV: Skhūl V, Ar: Arago, B: Bodo, K: Kabwe 1, JB1: Jebel Irhoud 1, P: Petralona, S: Salé) and Neandertals (red circle, F: Feldhofer, LC: LaChapelle-aux-Saints 1, LF1: La Ferrassie 1, Gu: Guattari, Gi: Gibraltar, K3: Krapina 3, Q5:La Quina H5, Sa: Saccopastore, TC1: Tabun C1, TT: Teshik Tash, , SII: Spy 10). Modified from [56]. / Graphique bivarié de la taille de la troisième circonvolution frontale (racine carrée, noté $3 F c$ ) et du volume endocrânien (racine cubique, noté Endo V) chez Pan paniscus (triangles), Pan troglodytes (triangles inversés), $\mathrm{H}$. sapiens (cercles), H. sapiens fossiles (cercles noirs), hominines fossiles (diamants noirs : $T$ : Taung, 17k : KNMWT 17000, 1470 : KNM-ER 1470, 1813 : KNM-ER 1813, 3733 : KNM-ER 3733, 3883 : KNM-ER 3883, 15k : KNMWT 15000, OH 9, D : Dmanisi 9002, T2: Trinil 2, S2 : Sangiran 2, S17: Sangiran 17, M : Mojokerto, Ng7: Ngandong 7, Ng12 : Ngandong 12, Sm3 : Sambungmacan 3, S3 :Zhoukoudian Ckn.E 1.PA.16, S12 : Zhoukoudian Ckn.L 2.PA.100, LB 1: Liang Bua 1, SV: Skhül V, Ar: Arago, B : Bodo, K: Kabwe 1, JB1 : Jebel Irhoud 1, P : Petralona, S: Salé) et Néandertaliens (cercle rouge, F: Feldhofer, LC : La Chapelle-aux-Saints 1, LF1: La Ferrassie 1, Gu : Guattari, Gi : Gibraltar, K3 : Krapina 3, Q5 : La Quina H5, Sa : Saccopastore, TC1 : Tabun C1, TT : Teshik Tash, SII : Spy 10). Modifié à partir de [56]. 